\title{
THE MECHANICAL PROPERTIES OF THE LUNGS IN PATIENTS WITH PERIODIC BREATHING
}

\author{
BY \\ DAVID MENDEL AND MALCOLM B. McILROY \\ From the Medical Professorial Unit, St. Bartholomew's Hospital and the Institute of Cardiology \\ Received October 18, 1956
}

Cheyne (1818) first described periodic breathing in " a case of apoplexy in which the fleshy part of the heart was converted into fat ". In describing the pattern of breathing he wrote: " his breathing was irregular; it would entirely cease for a quarter of a minute, then it would become perceptible, though very low, then by degrees it became heaving and quick, and then it would gradually cease again. This revolution in the state of his breathing occupied about a minute, during which there were about thirty acts of respiration." A similar case was described 36 years later by Stokes (1854) and since then the condition of Cheyne-Stokes breathing has been the subject of numerous papers. Although there has been a tendency to give the name of Cheyne-Stokes breathing to all forms of periodic breathing, it will be seen from the original description that it is more accurate to reserve the term for cases in which there is a definite period of apnœa and the length of the cycle is of the order of one minute.

As a result of the work of Pryor (1951), Gilmore and Kopelman (1954) and Guyton et al. (1955), it has been shown that changes in the activity of the respiratory centre and prolongation of the circulation time are important factors in the production of Cheyne-Stokes breathing. Periodic breathing occurs in patients with cerebral or cardiovascular disease and it has been suggested in the past that it is possible to distinguish a central and a peripheral type of periodic breathing. It is generally recognized that in patients with cerebral lesions, the cycle is shorter and apnœa is more likely to occur. Christie and Hayward (1943) suggested that the type of periodic breathing found in patients with left ventricular failure was due to waxing and waning pulmonary congestion. They measured the intra-pleural pressure and tidal volume in anæsthetized cats and rabbits and found that although the intra-pleural pressure swing remained constant the tidal volume underwent cyclic changes. Their findings could only be interpreted as indicating cyclical changes in the mechanical properties of the lung.

This paper reports the results of study of the mechanical properties of the lungs in patients with periodic breathing in which an attempt has been made to assess the part played by waxing and waning pulmonary congestion in the production of periodic breathing in man.

\section{Methods}

The mechanical properties of the lungs were measured from simultaneous records of intraœsophageal pressure and air flow. The patients, who were all sufficiently ill to make it difficult to obtain their co-operation, were studied sitting or semi-recumbent in bed. Intra-œsophageal pressure was measured either with a water filled tube (Dornhorst and Leathart, 1952) or a long air filled balloon (Mead et al., 1955) connected to an electromanometer. The tidal volume was measured by several different methods, none of which was entirely satisfactory. In most of the patients a spirometer or pneumotachograph was used and in the others a combined thoracic and abdominal pneumograph (Dornhorst and Leathart, 1952) gave a record that could be calibrated in terms of volume. The principal difficulty in the use of a spirometer or pneumotachograph is that the 
disturbance produced by breathing through a mouthpiece is often sufficient to abolish periodic breathing. The use of a pneumograph avoids this difficulty but is less accurate and difficult to calibrate.

The compliance of the lungs and the inspiratory resistance were measured, whenever possible, during the cycles of periodic breathing. In half the cases, however, the breathing became regular when the patient breathed through a mouthpiece. In these patients a record of intra-œsophageal pressure alone was obtained during periodic breathing and the mechanical properties of the lungs measured from the tracing taken when the breathing was regular. The length of the cycle of periodic breathing, the length of the period of apnœa, if present, and the respiratory rate were measured in each case. In one patient the oxygen saturation was measured with an ear oximeter.

RESULTS

The results in ten patients with periodic breathing are shown in Table I. All were men and all had evidence of cardiovascular disease. Four had classical Cheyne-Stokes breathing with a period

TABLE I

Results in Ten Patients With Periodic Breathing

\begin{tabular}{|c|c|c|c|c|c|c|c|c|c|c|}
\hline Name & Age & 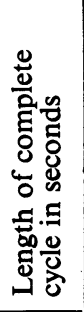 & 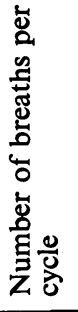 & 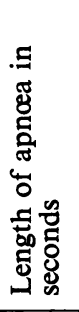 & 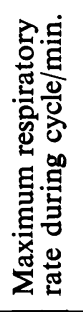 & 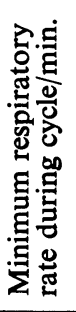 & 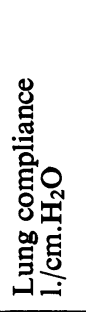 & 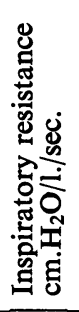 & 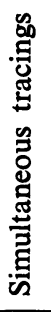 & Diagnosis and remarks \\
\hline A.L. & 49 & 48 & 13 & 10 & 20 & 一 & $0 \cdot 13$ & $2 \cdot 3$ & - & $\begin{array}{l}\text { Coronary thrombosis } \\
\text { Heart failure }\end{array}$ \\
\hline W.S. & 58 & 40 & 21 & - & 33 & 28 & $0 \cdot 13$ & $1 \cdot 9$ & + & $\begin{array}{l}\text { Cerebral hæmorrhage } \\
\text { Coronary thrombosis } \\
\text { Dissecting aneurysm (P.M.) }\end{array}$ \\
\hline A.S. & 58 & $\begin{array}{l}58 \\
58\end{array}$ & $\begin{array}{l}22 \\
14\end{array}$ & - & $\begin{array}{l}29 \\
28\end{array}$ & $\begin{array}{l}19 \\
-\end{array}$ & $\begin{array}{l}0.048 \\
0.034\end{array}$ & $\begin{array}{r}9 \cdot 6 \\
11 \cdot 6\end{array}$ & $\begin{array}{l}- \\
+\end{array}$ & $\begin{array}{l}\text { Coronary thrombosis } \\
\text { Heart failure }\end{array}$ \\
\hline G.C. & 59 & 30 & 7 & 11 & 23 & - & $0 \cdot 22$ & $2 \cdot 5$ & - & Uræmia \\
\hline C.A. & 62 & $\begin{array}{l}16 \\
17\end{array}$ & $\begin{array}{l}15 \\
12\end{array}$ & - & $\begin{array}{l}60 \\
60\end{array}$ & $\begin{array}{l}50 \\
-\end{array}$ & 0.040 & $6 \cdot 0$ & - & $\begin{array}{l}\text { Chronic bronchitis } \\
\text { Emphysema, hypertension } \\
\text { Heart failure }\end{array}$ \\
\hline M.J. & 66 & $\begin{array}{l}60 \\
56\end{array}$ & $\begin{array}{l}24 \\
14\end{array}$ & - & $\begin{array}{l}26 \\
26\end{array}$ & $\begin{array}{r}20 \\
-\end{array}$ & $\begin{array}{l}0.126 \\
0.084\end{array}$ & $\begin{array}{l}2 \cdot 6 \\
2 \cdot 8\end{array}$ & $\begin{array}{l}+ \\
-\end{array}$ & $\begin{array}{l}\text { Coronary thrombosis } \\
\text { Heart failure }\end{array}$ \\
\hline C.B. & 68 & 60 & 17 & 一 & 18 & 16 & $0 \cdot 14$ & 3.9 & - & $\begin{array}{l}\text { Malignant hypertension } \\
\text { Cerebral thrombosis } \\
\text { Heart failure (P.M.) }\end{array}$ \\
\hline F.S. & 69 & $\begin{array}{l}40 \\
38\end{array}$ & $\begin{array}{l}26 \\
22\end{array}$ & - & $\begin{array}{l}30 \\
30\end{array}$ & $\begin{array}{l}24 \\
23\end{array}$ & $\begin{array}{l}0.053 \\
0.049\end{array}$ & $\begin{array}{l}7 \cdot 0 \\
8 \cdot 5\end{array}$ & $\begin{array}{l}+ \\
+\end{array}$ & $\begin{array}{l}\text { 28.10.54. Hypertension } \\
\text { 26.5.55. Heart failure }\end{array}$ \\
\hline H.B. & 74 & 65 & 22 & - & 28 & 18 & 0.061 & $6 \cdot 3$ & + & $\begin{array}{l}\text { Coronary thrombosis } \\
\text { Heart failure (P.M.) }\end{array}$ \\
\hline C.G. & 74 & 60 & 26 & - & 28 & 21 & $0 \cdot 108$ & $4 \cdot 8$ & - & $\begin{array}{l}\text { Coronary thrombosis } \\
\text { Heart failure }\end{array}$ \\
\hline
\end{tabular}


of apnœa lasting 10-22 seconds and a cycle length of 30-58 seconds. Five had periodic breathing with a cycle length of 38-65 seconds but no period of apnea, while the other patient had a shorter cycle of 16-17 seconds with an apnœic period of 3 seconds on occasions. Two of the patients with classical Cheyne-Stokes breathing did not always have apnoa, in some cycles there was no apnœa while in others apnoa lasted up to 22 seconds.

It will be seen from Table I that the mechanical properties of the lungs varied considerably from patient to patient, being within normal limits in some and showing a marked reduction in compliance and an increase in respiratory resistance in others. A simultaneous tracing of intra-œsophageal pressure and tidal volume in patient F.S. is shown in Fig. 1. It will be seen that the pressure and volume tracings wax and wane together indicating a periodic variation in the force applied to the lungs, presumably due to periodic changes in the activity of the respiratory centre. This periodic fluctuation in the pressure record was seen in every patient studied and moreover there was no

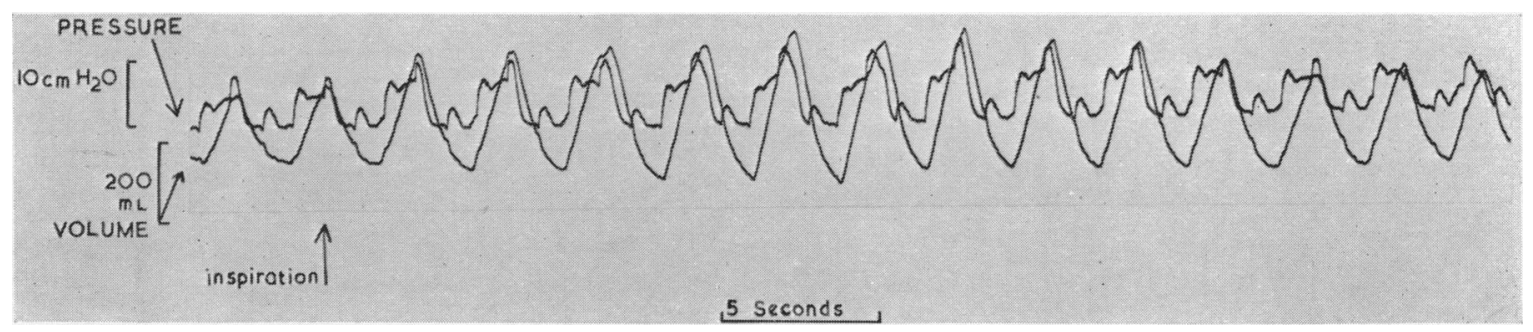

Fig. 1.-Tracing of intra-cesophageal pressure and tidal volume, showing periodic breathing in a patient with left ventricular failure.

consistent variation in the compliance and respiratory resistance measured from breath to breath throughout the cycle in the five patients in whom simultaneous tracings were obtained during periodic breathing.

A tracing of intra-œsophageal pressure in M.J. is shown in Fig. 2. In this patient there was a period of apnoea in some cycles but not in others and it will be seen that the respiratory rate and the pattern of the pressure tracing were essentially the same whether there was a period of apnoa or not. In the patient (C.A.) in whom oxygen saturation was measured, it was found to reach a maximum of 98 per cent during the apnœic period and a minimum of 91 per cent at the time of maximum hyperpnœa. This finding is similar to that previously reported by Klein (1930).

\section{Discussion}

If there is a form of periodic breathing due to waxing and waning pulmonary congestion, it should differ from that seen in patients with normal lungs and should not be associated with a period of apnœa, for apnœa must indicate a temporary cessation of activity of the respiratory centre.

We have found no evidence of waxing and waning pulmonary congestion in ten patients with heart disease and periodic breathing, in several of whom there was significant pulmonary congestion and no period of apnoa. In every patient the intra-œsophageal pressure tracings were compatible with cyclical changes in the activity of the respiratory centre and in no case was there evidence that the mechanical properties of the lungs changed from breath to breath throughout the cycle. We have not observed anything resembling the pattern reported by Christie and Hayward (1943) in animals in which the intra-pleural pressure fluctuations remained of constant amplitude while the tidal volume showed periodic breathing. It is, however, impossible to exclude the existence of such a form of periodic breathing. 
FIG. 2.-Tracings of intra-œsophageal pressure in a patient with periodic breathing. The upper tracing shows no apnœic period, while the lower tracing obtained several minutes later shows apnœa lasting 22 seconds.

\section{SUMMARY}

The mechanical properties of the lungs have been measured in ten patients with periodic breathing. The compliance of the lungs and the respiratory resistance varied, being within normal limits in some and grossly abnormal in others.

The intra-œsophageal pressure record in every case showed variations in the force applied to the lungs similar to those in tidal volume and there was no evidence that the mechanical properties of the lungs varied at different phases of the cycle of periodic breathing.

These findings support the conclusion that periodic fluctuations in the activity of the respiratory centre play an important part in the production of periodic breathing and indicate that waxing and waning pulmonary congestion was not a factor in the patients studied.

We wish to thank Dr. G. W. Hayward for his help and encouragement.

\section{REFERENCES}

Cheyne, J. (1818). Dublin Hosp. Reports, 2, 216.

Christie, R. V., and Hayward, G. W. (1943). J. Physiol., 102, 88.

Dornhorst, A. C., and Leathart, G. L. (1952). Lancet, 2, 109.

Gilmore, H. R., and Kopeman, H. (1954). Brit. med. J., 2., 1439

Guyton, A. C., Crowell, J. W., and Moore, J. (1955). Circulation, 12, 717.

Klein, O. (1930). Gesellsch. inn. Med., 42, 217.

Mead, J., McIlroy, M. B., Selverstone, N. J., and Kriete, B. C. (1955). J. appl. Phys., 7, 491.

Pryor, W. W. (1951). Circulation, 4, 233.

Stokes, W. (1854). Diseases of Heart and Aorta. Hodges and Smith, Dublin. 